\title{
Neurohospitalist
}

\section{A newly popular career choice}

\author{
S. Andrew Josephson, MD \\ Vanja C. Douglas, MD
}

\begin{abstract}
Summary
The rapid expansion of neurohospitalist programs nationally has been fueled by recent graduates as well as by practicing neurologists increasingly choosing this career direction. An inpatient-focused job is compelling from an intellectual perspective as it allows the opportunity to treat acute disorders where new treatments are constantly emerging. Challenges entail arranging coverage, defining financial models of reimbursement, expanding into rural and international settings, and assuring proper training for those entering this emerging field. A diverse set of opportunities in both practice and academics are viable career options. Those choosing to embark on the neurohospitalist path have the opportunity to lead the field through a time of tremendous growth and change for years to come.
\end{abstract}

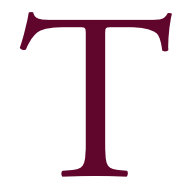

he recent tremendous growth of inpatient neurologic specialists could not have been fully anticipated when the concept was first detailed in the literature just a few short years ago. ${ }^{1,2}$ Neurohospitalists are now present in both academic and community settings across the United States. The Neurohospitalist Section of the American Academy of Neurology is one of the fastest growing in its history. The emergence of a subspecialty journal (The Neurohospitalist), multiple training opportunities, and research focused on this model of care have further legitimized the field as sustainable

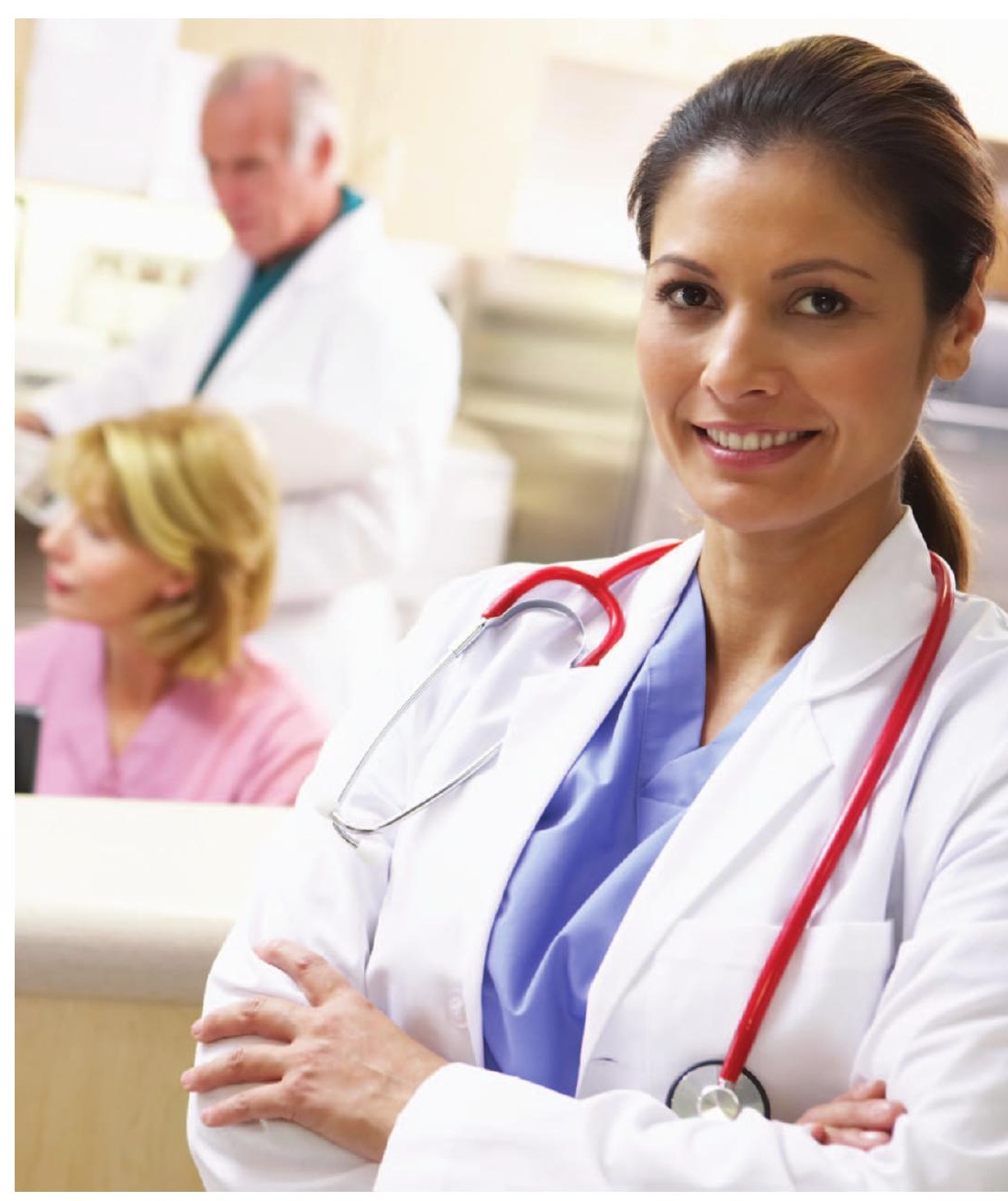
and likely to transform inpatient neurologic care. ${ }^{3}$ Increasing job opportunities for neurohospitalists have created a viable career choice that was not present just a decade ago, leading both recent trainees and practicing neurologists to embrace the opportunity to focus on inpatient neurology.

The separation of inpatient and outpatient neurology has been driven in part by many of the same pressures that led to a similar division in internal medicine nearly 2 decades ago. With the emergence of multiple treatment options for acute neurologic illnesses, neurologists

Department of Neurology, San Francisco, California.

Correspondence to: ajosephson@memory.ucsf.edu 


\section{Whether one performs consultations or has admitting privileges in the hospital, the neurohospitalist model provides an opportunity to work closely with colleagues across multiple medical and surgical specialties.}

are increasingly expected to be present continuously in the Emergency Department (ED) and throughout the hospital to deliver time-sensitive assessments and therapies. At the same time, financial pressures from insurers have raised the bar for inpatient admission and heightened the focus on decreasing lengths of stay, leading to hospitalized patients with a higher acuity of illness than in the past. Combined with financial and time stressors in the clinic, neurologists are increasingly challenged to squeeze inpatient medicine into a busy outpatient practice. In addition, increased focus and scrutiny across all inpatient medicine on quality metrics, safety, and patient satisfaction has led to an increased work load and time requirement for those caring for inpatients. This confluence of factors has made the neurohospitalist model a logical solution in many health care settings.

\section{The draw of an inpatient-based career}

While these financial and regulatory pressures may have created the opportunity for growth of the neurohospitalist model, ultimately the expansion of the field has been fueled by the career choices of individual physicians. During residency training, which remains relatively inpatient-focused at many programs, house staff become comfortable with the wide range of acute neurologic diseases. Immediately following training, an inpatient-based career may provide a level of familiarity and comfort that is reassuring to young neurologists.

From an intellectual perspective, a neurohospitalist career offers the opportunity to spend time caring for a range of acute disorders where new treatments are constantly emerging. Rather than training in a specific field of neurology (e.g., movement disorders, epilepsy), the neurohospitalist can keep a broad generalist perspective while participating in the care of inpatients across multiple subspecialties. Overlaps between neurohospitalists and vascular neurology as well as neurocritical care further provide a diverse exposure that encompasses many of the fields most attractive to young trainees, who remain committed to caring for patients with stroke and intensive care unit (ICU)-related neurologic disorders despite not focusing exclusively on either of these inpatient-based subspecialties.

Whether one performs consultations or has admitting privileges in the hospital, the neurohospitalist model provides an opportunity to work closely with colleagues across multiple medical and surgical specialties. For example, in most hospitals, neurohospitalists have the advantage of providing an active, immediately available consultative role for patients in the ICU, partnering with medical critical care physicians to improve the neurologic care of these patients; in hospitals with dedicated neurocritical care teams, the neurohospitalist may be able to provide supplemental coverage, filling gaps and providing continuity of care when these patients leave the ICU. The draw of many to neurology involved its close relationship with internal medicine, and working as a neurohospitalist allows one to continue to manage a broad set of medical problems in hospitalized inpatients.

The internal medicine hospitalist movement was initially populated by an extremely young workforce in part driven by the attractiveness of a career with predictable hours and shift work. ${ }^{4}$ If set up in this fashion, a neurohospitalist career may have similar advantages to specialties such as emergency medicine in which hours are firmly set and time spent charting and calling patients and insurers outside of the work day is minimal. This schedule may be viewed by some as more "family friendly" than those with less predictable time commitments 
and therefore may be more attractive to young neurologists. Of course, looming large over any specialty with shift work is the danger of burnout, a concern that must be addressed moving forward in the neurohospitalist world.

\section{Challenges to the neurohospitalist care model}

An important consideration for any neurohospitalist position involves scheduling and arranging a call schedule. The length (e.g., 12 hours vs 8 hours) and frequency of shifts (e.g., clustered shifts daily for 5-7 days followed by a block of shifts off vs a more scattered approach) are highly variable across neurohospitalist jobs nationally. However, the key "sticking points" for job satisfaction and burnout usually involve night and weekend coverage. Neurohospitalist groups need to decide whether coverage is continually provided in-house or alternatively make arrangements with hospitals and EDs to have home call, perhaps with backup from internal medicine or other hospital-based physicians.

With primary stroke center certification, neurohospitalists are facing increasing pressure to be present in person within a short time frame when a patient arrives to the ED with an acute cerebrovascular event. Some hospitals have adopted a model where all acute stroke calls are managed by neurohospitalists even if the rest of inpatient call is split between inpatient and outpatient groups. How neurohospitalists provide this type of emergency coverage regardless of the day of the week or time of day remains a key problem. Much of the discussion often comes down to manpower and volume. While any inpatient specialty would strive to have 24-hour coverage that is consistent, unlike our colleagues in internal medicine, the relative size of our specialty may limit the number of neurohospitalists at any single hospital. This creates gaps in coverage that need to be filled and negotiated, at times using creative solutions. In hospitals with a low volume of acute neurologic emergencies, the need for coverage outside of the usual weekly schedule may be much less.

Financial considerations loom large for neurohospitalists as with any new model of care, especially in the setting of recently decreased reimbursement and increased regulatory oversight. It remains to be seen if patient volume and reimbursement are adequate to sustain a purely inpatient-based neurology practice in most hospitals. It is possible that hiring neurohospitalists would enable a private practice group to maximize their outpatient efficiency and the resulting revenue could subsidize the neurohospitalists' salary. In addition, an increasing number of neurohospitalists receive salary support directly from hospitals in order to create a coverage solution for an institution, achieve accreditation as a Primary Stroke Center, or to be marketed as a neurology or neuroscience center of excellence. This model requires neurohospitalists to directly negotiate with hospitals to determine salary, schedules, and expectations. In some hospitals, additional stipends have been provided to neurohospitalists beyond their base salary as incentives for night and weekend coverage. These arrangements, meant to offset the inconvenience of a 24-hour call cycle and to increase consult volume, have historically been much more common with surgical subspecialties.

An additional consideration when neurohospitalists act as hospital employees is that they are often asked to serve (with or without additional compensation) on hospital committees, as medical directors, or as stewards of quality and safety metrics for neurologic patients. If the

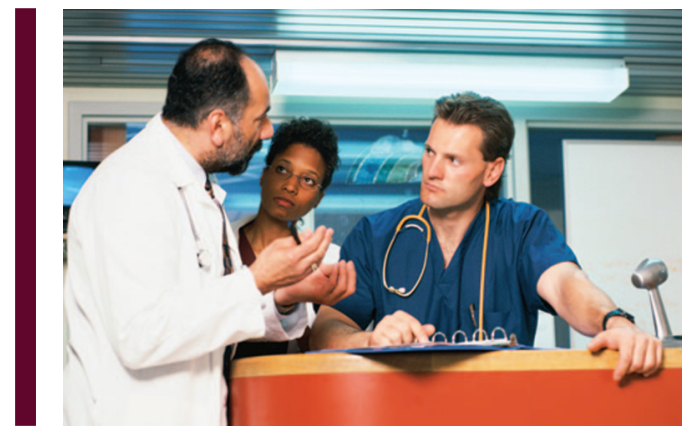

Financial considerations loom large for neurohospitalists as with any new model of care, especially in the setting of recently decreased reimbursement and increased regulatory oversight. 


\section{Neurohospitalist groups need to decide} whether coverage is continually provided in-house or alternatively make arrangements with hospitals and EDs to have home call, perhaps with backup from internal medicine or other hospital-based physicians.

neurohospitalist has interest in these types of administrative tasks, the arrangement can be beneficial to both parties and help justify direct financial support.

A wide range of salaries have been advertised for neurohospitalist jobs nationally. As with any other neurology position, it is likely that regional and local forces of supply and demand will ultimately drive the market. From initial surveys of this emerging field it does not yet seem that there is a large discrepancy between neurohospitalist and outpatient neurology salaries. ${ }^{5}$ If this equity stands the test of time, it would be ideal, as graduates would be able to choose between inpatient and outpatient-focused careers without the pressures of disparate financial gain as has been the case with some other specialties (e.g., outpatient cardiology vs interventional cardiology).

A further challenge to the neurohospitalist model involves its spread to areas outside of major cities and large hospitals. Rural hospitals may have neither the volume of neurologic patients nor the number of neurologists to justify a position with a primarily inpatient focus. The emergence of telemedicine may be one approach to this problem, allowing neurohospitalists to provide remote coverage and perhaps design call schedules in partnership with local neurologists.

There has been relatively little experience with neurohospitalists internationally, but the model would seem to be attractive and applicable outside of the United States in countries with similar health care systems. Much like the spread of internal medicine hospitalists internationally, it is anticipated that the worldwide expansion of the neurohospitalist model would lag a few years behind its inception in the United States. ${ }^{6}$ Certainly in developing countries, where in many cases a severe shortage of neurologists exists, the model is unlikely to become a primary method of delivering neurologic care anytime soon; however, research into ideal methods of inpatient neurologic care may help inform non-neurologic hospital-based specialists caring for these underserved populations.

\section{Training neurohospitalists}

As with any career choice, it is important that graduates receive proper training in order to be competent and comfortable with clinical practice. Over the past 5 years, a number of neurohospitalist fellowships have emerged, including ours at the University of California, San Francisco. Established programs have now been joined by a quickly expanding range of newly formed fellowships, providing many options for those who wish to pursue this additional training.

Although the structure of these often 1-year programs vary, the fellowship typically involves more intensive clinical exposure to inpatient neurology including vascular neurology and possibly neurocritical care. For those trainees interested in building a career as an academic neurohospitalist or as a neurohospitalist with substantial administrative responsibilities, many fellowship programs have built in dedicated research time to explore issues surrounding models of care as well as quality and safety, while allowing trainees to hone their teaching and team leadership skills by supervising residents.

It is likely that some graduates looking toward a future as a neurohospitalist will not pursue fellowship training as they will feel comfortable with their inpatient skills immediately postresidency due to previous training in an inpatient-intense environment. ${ }^{7}$ However, with a 
shift toward more outpatient experiences in the residency and decreased patient contact hours in the setting of duty hour limitations, residents are graduating with less inpatient experience than in the past and many more will likely see the benefit of additional training prior to beginning their neurohospitalist careers.

\section{The academic neurohospitalist}

Although purely patient care-oriented career choices in neurology have traditionally been most prevalent in private practice, neurohospitalists are increasingly being employed in university settings, providing yet another career option for those who desire an inpatient focus. Many neurology departments have seen neurohospitalist programs as a solution to mandates for increased oversight of residents and students, financial pressures, and the challenges of caring for an inpatient population with higher acuity. The same forces that have driven the separation of inpatient and outpatient neurology in practice are now being felt in academic departments with a resulting expansion of academic neurohospitalist programs.

In addition to patient care, academic neurohospitalists are playing major roles in administration, teaching, and research, the latter focusing on validating neurohospitalist models of care as well as addressing specific issues surrounding quality metrics and safety in the inpatient neurologic arena. ${ }^{8}$ Departments have begun to develop promotion tracks by which these individuals can advance and flourish in an academic environment, and many are rethinking the traditional model of "submarining" researchers or outpatient-based faculty who spend 2 or 4 weeks per year as inpatient attendings. While financial models remain challenging in a world of ever-shrinking reimbursement, many universities are taking lessons from private neurohospitalist structures, garnering financial support for these positions from the medical centers in which the neurohospitalists function.

A neurohospitalist career has emerged as a viable option in diverse settings: for recent graduates or those already in practice, in academics and in private practice, and in large cities as well as in smaller communities. The next phase of growth for this specialty will involve important decisions regarding the financial sustainability of this model and issues involving scheduling and quality of life for those who choose this path. There is much work to be done to define the field moving forward, and it is unlikely that a "one size fits all" approach will be useful in such diverse settings. This is an exciting time to be part of this growing field where opportunities abound, challenges remain, and where the future seems incredibly bright.

\section{REFERENCES}

1. Josephson SA, Engstrom JW, Wachter RM. Neurohospitalists: an emerging model for inpatient neurological care. Ann Neurol 2008;63:135-140.

2. Freeman WD, Gronseth G, Eidelman BH. Invited article: is it time for neurohospitalists? Neurology 2008;70:1282-1288.

3. Freeman WD, Josephson SA. The birth of neurohospitalists. Neurohospitalist 2011;1:5-7.

4. Glasheen JJ, Misky GJ, Reid MB, Harrison RA, Sharpe B, Auerbach A. Career satisfaction and burnout in academic hospital medicine. Arch Intern Med 2011;171:782-785.

5. Likosky D, Shulman S, Restrepo L, Freeman WD. Survey of neurohospitalists: Subspecialty definition and practice characteristics. Front Neurol 2010;1:9.

6. Lee KH. The hospitalist movement: a complex adaptive response to fragmentation of care in hospitals. Ann Acad Med Singapore 2008;37:145-150.

7. Barrett KM, Fowler MV. Is fellowship training necessary for neurohospitalists? Neurohospitalist 2011; $1: 125-127$.

8. Douglas VC, Josephson SA. Proposed roadmap for inpatient neurology quality indicators. Neurohospitalist $2011 ; 1: 8-15$.

\section{DISCLOSURES}

Dr. Josephson serves as an Associate Editor for Annals of Neurology and The Neurohospitalist and as Editor-InChief for Journal Watch Neurology. Dr. Douglas serves as Editor-In-Chief of The Neurohospitalist. 


\section{Related articles from other AAN physician and patient resources}

Neurology ${ }^{\circledR} \bullet \quad$ www.neurology.org

Teaching the next generation of neurologists.

February 17, 2009;72:657-663.

\section{Continuum ${ }^{\circledR} \quad$ - www.aan.com/go/elibrary/continuum}

Neurologic consultation in the hospital.

October 2011

Neurology Today ${ }^{\circledR} \quad$ www.neurotodayonline.com

Where the jobs are: The future for newly minted neurologists.

September 1, 2011;11:32-33.

Career Tracks: Neurohospitalist movement growing rapidly-More fellowships, a new journal, and an AAN section.

April 7, 2011;11:56-57.

More neurologists living la vida locum: The pros and cons.

September 16, 2010;10:28,29,32. 


\section{Neurology ${ }^{\circ}$ Clinical Practice}

Neurohospitalist: A newly popular career choice

S. Andrew Josephson and Vanja C. Douglas

Neurol Clin Pract 2011;1;55-60

DOI 10.1212/CPJ.0b013e31823c8856

This information is current as of December 1, 2011

Updated Information \&
Services

Citations

Subspecialty Collections

Permissions \& Licensing

Reprints including high resolution figures, can be found at:

http://cp.neurology.org/content/1/1/55.full.html

This article has been cited by 3 HighWire-hosted articles:

http://cp.neurology.org/content/1/1/55.full.html\#\#otherarticles

This article, along with others on similar topics, appears in the following collection(s):

Medical care

http://cp.neurology.org//cgi/collection/medical_care

Patient safety

http://cp.neurology.org//cgi/collection/patient_safety

Quality of life

http://cp.neurology.org//cgi/collection/quality_of_life

Information about reproducing this article in parts (figures,tables) or in its entirety can be found online at:

http://cp.neurology.org/misc/about.xhtml\#permissions

Information about ordering reprints can be found online:

http://cp.neurology.org/misc/addir.xhtml\#reprintsus

Neurol Clin Pract is an official journal of the American Academy of Neurology. Published continuously since 2011, it is now a bimonthly with 6 issues per year. Copyright Copyright $₫ 2011$ by AAN Enterprises, Inc.. All rights reserved. Print ISSN: 2163-0402. Online ISSN: 2163-0933.

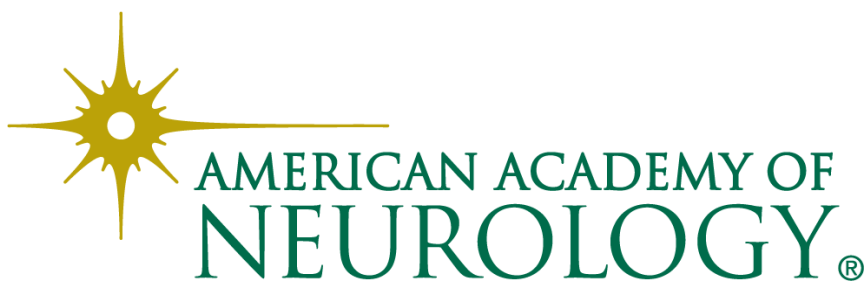

